\title{
A EDUCAÇÃO SUPERIOR NO BRASIL: INSUMOS, INDICADORES E COMPARAÇÕES COM PAÍSES DA OCDE E DO BRICS*
}

\author{
Nelson Cardoso Amaral \\ da Universidade Federal de Goiás (UFG).
}

\begin{abstract}
Resumo: O estudo apresenta uma série de indicadores associados à educação superior e compara os dados do Brasil com aqueles dos países membros da OCDE e do BRICS. Os resultados das análises mostram que, em geral, são grandes os desafios do Brasil quando comparados seus indicadores aos dos países da OCDE. Pode-se concluir que só será possível atingir os parâmetros da OCDE quando ocorrerem, simultaneamente, três efeitos: estabilidade da população com a diminuição de crianças e jovens em idade educacional; crescimento do país e de seu PIB, no contexto do capitalismo mundial; e diminuição das desigualdades sociais existentes.
\end{abstract}

Palavras-Chave: Educação superior. Indicadores. Percentual do PIB. Orçamento.

O presente texto analisa diversos indicadores associados à educação superior no Brasil e tece comparações com os países que compõem a Organização para Coordenação e Desenvolvimento Econômico (OCDE) e com os países que fazem parte do BRICS (Brasil, Rússia, Índia, China e África do Sul). Os países da OCDE são aqueles mais ricos do mundo e possuem uma renda per capita média de US\$/PPP $134.062,00$, e os países que compõem o BRICS, com renda per capita média de US\$/PPP 10.280,00, cada vez mais se fazem presentes no cenário internacional, que

está sendo transformado pela crescente presença dos países emergentes. Tais países não só agiram como elementos de sustentação da economia mundial, depois da crise de 2008, por manterem taxas expressivas de crescimento,

\footnotetext{
* Artigo recebido em 14/10/2012 e aprovado em 05/12/2012.
} 
como também se tornaram polos de expansão do comércio internacional, via incremento de exportações e importações. (THORSTENSEN, 2011, p.7)

Dentre os países que compõem a OCDE examinaremos, em separado, os indicadores do Chile, da Hungria, do México e da Turquia, pois esses, apesar de fazerem parte da OCDE, possuem rendas per capita mais próximas às dos BRICS; a do Chile é de US\$/PPP 16.100,00; da Hungria, US\$/PPP 19.600,00; do México, US\$/PPP 15.100,00; e da Turquia, US\$/PPP 14.600,00.

Ao examinarmos diversos indicadores relativos à educação superior, poderemos perceber as diferenças existentes entre o Brasil e demais países que compõem o BRICS e aqueles da OCDE - aqui denominados de "bloco" da OCDE: países da Organização, menos o Chile, a Hungria, o México e a Turquia - que já possuem uma situação cristalizada no contexto da constituição mundial em uma sociedade estruturada no modo capitalista de produção (HARVEY, 2000, p.131).

São muitos os aspectos pertinentes à educação superior que serão abordados: a relação entre o público e o privado; o nível de acesso da população à educação superior; os recursos financeiros que constituem fundo público (AMARAL, 2003) aplicados em educação; os recursos públicos aplicados por estudante matriculado no país; a distribuição de salários, outras despesas correntes e capital nas instituições de educação superior (IES); a relação aluno/professor nas IES; os recursos totais aplicados na educação do país e os gastos por pessoa em idade educacional.

Para a realização deste estudo foram utilizadas várias fontes na obtenção das informações, destacando-se, em âmbito brasileiro, os bancos de dados do(a): Coordenação de Aperfeiçoamento de Pessoal de Nível Superior (Capes), Ministério da Educação (MEC), Instituto Brasileiro de Geografia e Estatística (IBGE) e Ministério da Fazenda (MF). Em âmbito internacional foram utilizados os bancos de dados dos seguintes organismos: Organização para a Coordenação e Desenvolvimento Econômico (OCDE), Banco Mundial, Central Intelligence Agency (CIA) e Organização das Nações Unidas para a Educação, Ciência e Cultura (Unesco).

Em primeiro lugar, apresentaremos um estudo que procura avaliar quais países, dentre os selecionados, possuem maiores dificuldades para resolver seus problemas educacionais; em seguida, serão analisados os indicadores associados às seguintes temáticas: o público e o privado; os recursos aplicados em educação por estudante matriculado; os insumos financeiros das IES - salários, outras despesas correntes e capital; e a relação aluno/professor. 


\section{A RIQUEZA DOS PAÍSES E O TAMANHO DOS DESAFIOS EDUCACIONAIS}

A riqueza de um país pode ser medida pelo seu Produto Interno Bruto (PIB), que é a soma de todos os bens e serviços finais produzidos dentro de um país, independentemente da nacionalidade dos proprietários das unidades produtoras desses bens e serviços; inclui, portanto, a produção de empresas estrangeiras que atuam no país.

Podemos examinar o tamanho dos desafios educacionais de um país, considerando os percentuais do PIB que são destinados à educação e calculando o valor aplicado por pessoa em idade educacional, comparado com o valor designado pelos países do "bloco" da OCDE (AMARAL, 2011).

O quantitativo de pessoas em idade educacional é obtido adicionando-se aqueles em idade de pre-primary (creche e pré-escola no Brasil, idade de 0 a 5 anos), em idade de primary (anos iniciais do ensino fundamental no Brasil, $1 .^{\circ}$ ao $5 .^{\circ}$ ano, idade de 6 a 10 anos), em idade de lower secondary (anos finais do ensino fundamental no Brasil, 6..$^{\circ}$ ao 9. ${ }^{\circ}$ ano, idade de 7 a 14 anos), em idade de upper secondary (ensino médio no Brasil, idade de 15 a 17 anos) e em idade de tertiary (educação superior no Brasil, idade de 18 a 24 anos).

A Tabela 01 mostra o valor aplicado por pessoa em idade educacional e o fator multiplicativo (FM) para se atingir o valor dos países do "bloco" da OCDE. Pode-se considerar que quanto maior o fator multiplicativo, maiores serão os desafios educacionais para aquele país.

Tabela 1 - Valor aplicado por pessoa em idade educacional e FM, para se atingir o valor da OCDE.

\begin{tabular}{|l|c|c|c|c|c|c|}
\hline \multicolumn{1}{|c|}{ País } & $\begin{array}{c}\text { PIB } \\
\text { (US\$\$PPP } \\
\text { em } \\
\text { bilhões) } \\
\mathbf{2 0 1 1}\end{array}$ & $\begin{array}{c}\text { \% PIB } \\
\text { aplicado } \\
\text { em } \\
\text { educação }\end{array}$ & $\begin{array}{c}\text { População } \\
\text { em idade } \\
\text { educacional }\end{array}$ & $\begin{array}{c}\text { Valor } \\
\text { aplicado em } \\
\text { educação } \\
\text { em bilhões } \\
\text { (US\$/PPP) }\end{array}$ & $\begin{array}{c}\text { Valor aplicado } \\
\text { por pessoa } \\
\text { em idade } \\
\text { educacional } \\
\text { (US\$/PPP) }\end{array}$ & $\begin{array}{c}\text { Fator de } \\
\text { Multiplicação } \\
\text { para atingir o } \\
\text { valor da OCDE }\end{array}$ \\
\hline Brasil & $2.380,00$ & 5,08 & 64.054 .997 & 120,904 & $1.887,50$ & 4,2 \\
\hline $\begin{array}{l}\text { "Bloco" da } \\
\text { OCDE }\end{array}$ & $39.675,00$ & 5,17 & 257.833 .181 & $2.050,03$ & $7.950,98$ & 1,0 \\
\hline Rússia & $2.380,00$ & 3,9 & 35.043 .319 & 92,82 & $2.648,72$ & 3,0 \\
\hline Índia & $4.463,00$ & 3,1 & 557.261 .930 & 138,353 & 248,27 & 32,0 \\
\hline China & $11.290,00$ & 3,3 & 415.339 .912 & 372,57 & 897,02 & 8,9 \\
\hline África do Sul & 555,00 & 5,4 & 20.105 .821 & 29,97 & $1.490,61$ & 5,3 \\
\hline Chile & 281,00 & 4,0 & 5.380 .607 & 11,24 & $2.088,98$ & 3,8 \\
\hline Hungria & 195,0 & 5,2 & 2.661 .708 & 10,16 & $3.815,44$ & 2,1 \\
\hline México & $1.657,00$ & 4,8 & 41.354 .774 & 79,54 & $1.923,26$ & 4,1 \\
\hline Turquia & $1.026,00$ & 2,9 & 24.266 .277 & 29,75 & $1.226,15$ & 6,5 \\
\hline
\end{tabular}

Fonte: UNESCO, 2010; EUA.CIA, 2010 e cálculos deste estudo. 
A Índia, com um fator multiplicativo de 32,0, seria, nessa análise, o país com maiores desafios educacionais; em seguida, a China, com o fator de 8,9; e a Turquia, com 6,5. A Hungria, com fator multiplicativo de 2,1, e a Rússia, com 3,0, estariam mais próximas de conseguir aplicar US\$/PPP 7.950,98 por pessoa em idade educacional - média do "bloco" da OCDE. O Brasil, com FM de 4,2, África do Sul, com 5,3 e o México, com 4,1, estariam longe de poderem alcançar o valor médio do "bloco" da OCDE. Esses países teriam que aplicar recursos financeiros em percentuais muito elevados do PIB; o Brasil precisaria aplicar 21,3\%, a África do Sul, 28,6\%, e o México, 9,68\%, para alcançarem os valores médios da OCDE. Pode-se asseverar que são percentuais inaplicáveis, considerando-se as carências desses países em outros setores sociais.

A relação percentual entre a população em idade educacional e a população total do país pode dar, também, uma indicação das dificuldades para se solucionarem os seus problemas educacionais. A Tabela 02 apresenta essa relação para os países em estudo.

Tabela 2 - População em idade educacional em relação à população do país.

\begin{tabular}{|l|c|c|c|}
\hline País & $\begin{array}{c}\text { População total do país } \\
\text { (A) }\end{array}$ & $\begin{array}{c}\text { População em idade } \\
\text { educacional } \\
\text { (B) }\end{array}$ & \% B/A \\
\hline Brasil & 205.760 .890 & 64.054 .997 & 31,1 \\
\hline "Bloco" da OCDE & 1.250 .451 .497 & 257.833 .181 & 20,6 \\
\hline Rússia & 138.082 .178 & 35.043 .319 & 25,4 \\
\hline Índia & 1.205 .073 .612 & 557.261 .930 & 46,2 \\
\hline China & 1.343 .239 .923 & 415.339 .912 & 30,9 \\
\hline África do Sul & 48.810 .427 & 20.105 .821 & 41,2 \\
\hline Chile & 17.067 .369 & 5.380 .607 & 31,5 \\
\hline Hungria & 9.958 .453 & 2.661 .708 & 26,7 \\
\hline México & 114.975 .406 & 41.354 .774 & 36,0 \\
\hline Turquia & 79.749 .461 & 24.266 .277 & 30,4 \\
\hline
\end{tabular}

Fonte: UNESCO, 2010; EUA.CIA, 2010 e cálculos deste estudo.

Com exceção da Rússia, com $25,4 \%$ de sua população em idade educacional, e da Hungria, com $26,7 \%$, e dos países do "bloco" da OCDE, com o percentual médio de $20,6 \%$, todos os demais países apresentam percentuais mais elevados - acima de 30\%. A Índia chegando a 46,2\%, África do Sul a 41,2\% e o México a $36,0 \%$. O Brasil, a Turquia e a China encontram-se no limite dos $30 \%$, com $31,1 \%, 30,9 \%$ e $30,4 \%$, respectivamente. 
O PÚBLICO E O PRIVADO NA EDUCAÇÃO

Os recursos financeiros que estruturam a educação de um país ou se originam dos fundos públicos ou são recursos privados. Os recursos financeiros que compõem os fundos públicos são responsáveis por manter as escolas e instituições públicas que oferecem os diversos níveis educacionais. Em geral, há um grande percentual de matrículas públicas nos níveis básicos da educação (pré-primary, primary, e secondary e pós-secondary); no nível superior (tertiary), há uma grande variação entre o percentual público e o percentual privado nos diversos países do mundo. A Tabela 03 mostra os percentuais de matrículas públicas nos diversos níveis educacionais, nos países em estudo.

Tabela 3 - Percentual público no nível educacional.

\begin{tabular}{|l|c|c|c|c|c|c|}
\hline País & Pré-Primary & Primary & $\begin{array}{r}\text { Lower } \\
\text { Secondary }\end{array}$ & $\begin{array}{c}\text { Upper } \\
\text { Secondary }\end{array}$ & $\begin{array}{c}\text { Post- } \\
\text { Secondary }\end{array}$ & Tertiary \\
\hline Brasil & 74 & 87 & 89 & 84 & - & 26 \\
\hline “Bloco” da OCDE & 67 & 82 & 80 & 81 & 66 & 95 \\
\hline Rússia & 99 & 99 & 99 & 99 & 100 & 85 \\
\hline Índia & - & - & - & - & - & - \\
\hline China & 57 & 95 & 92 & 88 & 100 & - \\
\hline África do Sul & 95 & 97 & 97 & 97 & 100 & - \\
\hline Chile & 43 & 42 & 47 & 41 & - & 20 \\
\hline Hungria & 94 & 92 & 91 & 85 & 77 & 84 \\
\hline México & 85 & 92 & 89 & 82 & - & 67 \\
\hline Turquia & 91 & - & - & 97 & - & 94 \\
\hline
\end{tabular}

Fonte: UNESCO, 2010 e OCDE, 2011.

O Brasil possui um elevado percentual de matrículas privadas na educação superior, próximo de $74 \%$ das matrículas, sendo que a média dos países do "bloco" da OCDE é de $5 \%$. O Chile também possui uma educação superior altamente privatizada, com $80 \%$ das matrículas nesse setor. O número total de matrículas nos países pode ser avaliado quando se examina a taxa bruta de matrículas (TBM) nesse nível educacional, que é o quantitativo de matrículas na educação superior, dividido pelo número de jovens em idade educacional apropriada para realizarem um curso superior de graduação. $A$ Tabela 04 apresenta a TBM para os países em análise e os fatores multiplicativos para se atingir a TBM média dos países do "bloco" da OCDE. 
Tabela 4 - Taxa bruta de matrículas (TBM) e FM para o "bloco" da OCDE.

\begin{tabular}{|l|r|r|r|c|}
\hline País & $\begin{array}{r}\text { Tertiary } \\
\text { matrículas }\end{array}$ & $\begin{array}{c}\text { População em } \\
\text { idade tertiary }\end{array}$ & Taxa bruta \% & $\begin{array}{c}\text { Fator de } \\
\text { multiplicação para o } \\
\text { "bloco" da OCDE }\end{array}$ \\
\hline Brasil & 6.115 .138 & 16.544 .273 & 37 & 1,8 \\
\hline "Bloco" da OCDE & 43.451 .807 & 64.635 .801 & 67 & 1,0 \\
\hline Rússia & 9.330 .115 & 12.294 .605 & 76 & 0,9 \\
\hline Índia & 18.648 .923 & 116.081 .527 & 16 & 4,2 \\
\hline China & 31.046 .735 & 110.657 .539 & 28 & 2,4 \\
\hline África do Sul & - & 5.073 .842 & - & - \\
\hline Chile & 876.243 & 1.501 .257 & 58 & 1,2 \\
\hline Hungria & 424.679 & 644.694 & 66 & 1,0 \\
\hline México & 2.705 .190 & 10.607 .597 & 26 & 2,6 \\
\hline Turquia & 2.924 .281 & 6.382 .284 & 46 & 1,5 \\
\hline
\end{tabular}

Fonte: UNESCO, 2010 e cálculos deste estudo.

A taxa bruta da Índia é de $16 \%$, do México é de $26 \%$, da China é de $28 \%$ e do Brasil é de $37 \%$. Para atingirem os elevados percentuais já alcançados pelos países do "bloco" da OCDE, Rússia, Hungria e Chile, os outros países terão que realizar uma grande expansão de seus sistemas terciários: a Índia possui um fator de 4,2; o México, 2,6; a China, 2,4; e o Brasil e a Turquia, 1,8 e 1,5 , respectivamente.

Entretanto, as desigualdades sociais presentes nesses países impedem que exista uma grande expansão do setor privado pela impossibilidade de as famílias efetuarem o pagamento de mensalidades, o que já está ocorrendo no Brasil (AMARAL, 2003); há, portanto que se fazer um enorme esforço para a expansão da educação superior pública.

\section{OS RECURSOS PÚBLICOS APLICADOS EM EDUCAÇÃO, POR ESTUDANTE MATRICULADO}

A impossibilidade - pela falta de informações - em separar, para a maioria dos países em estudo, quantos são os estudantes matriculados no setor público e no setor privado e, também, que volume de recursos financeiros - como percentual do PIB - é aplicado nos níveis básico e superior, nos impede de calcular com precisão qual montante de recursos públicos é destinado à educação superior, por estudante matriculado. Entretanto, se avaliarmos os recursos públicos aplicados em educação, por estudante matriculado, sem separá-los em público ou privado, podemos obter informações que nos permitem fazer análises relativas entre os países. É preciso lembrar que já fizemos, neste estudo, uma primeira abordagem nessa 
direção, considerando o quantitativo da população em idade educacional e não o número de alunos matriculados. A Tabela 5 apresenta essa informação.

Tabela 5 - Recursos por aluno matriculado e FM para atingir o valor da OCDE.

\begin{tabular}{|l|c|c|c|c|}
\hline País & $\begin{array}{c}\text { Valor aplicado } \\
\text { em educação } \\
\text { US\$/PPP em } \\
\text { bilhões }\end{array}$ & $\begin{array}{c}\text { Número total } \\
\text { de estudantes } \\
\text { matriculados }\end{array}$ & $\begin{array}{c}\text { Recursos por } \\
\text { estudante } \\
\text { matriculado em } \\
\text { US\$\$PPP }\end{array}$ & $\begin{array}{c}\text { Fator de } \\
\text { multiplicação } \\
\text { para OCDE }\end{array}$ \\
\hline Brasil & 120,90 & 53.994 .340 & $2.239,12$ & 4,3 \\
\hline “bloco" da OCDE & $2.050,03$ & 212.731 .462 & $9.636,70$ & 1,0 \\
\hline Rússia & 92,82 & 29.199 .139 & $3.178,86$ & 3,0 \\
\hline Índia & 138,35 & 307.265 .006 & 450,26 & 21,4 \\
\hline China & 372,57 & 258.067 .128 & $1.443,69$ & 6,7 \\
\hline África do Sul & 29,97 & - & & - \\
\hline Chile & 11,24 & 4.430 .020 & $2.537,23$ & 3,8 \\
\hline Hungria & 10,16 & 2.102 .193 & $4.833,05$ & 2,0 \\
\hline México & 79,54 & 33.686 .729 & $2.361,17$ & 4,1 \\
\hline Turquia & 29,75 & 17.421 .613 & $1.707,65$ & 5,6 \\
\hline
\end{tabular}

Fonte: UNESCO, 2010; EUA.CIA, 2010 e cálculos deste estudo.

O valor médio aplicado pelos países do "bloco" da OCDE atingiu US\$/ PPP 9.636,70 por aluno matriculado (público e privado), sendo que a Índia exige um fator multiplicativo muito elevado, de 21,4, para alcançar os valores do "bloco" da OCDE. O Chile, a Hungria, o México e a Turquia, mesmo sendo membros da OCDE, possuem ainda fatores multiplicativos que podem ser considerados elevados, de 3,8, 2,0, 4,1 e 5,6, respectivamente. O Brasil, para atingir o valor médio do "bloco" da OCDE, precisa multiplicar por 4,3 os valores financeiros aplicados na educação da sua população.

\section{OS INSUMOS FINANCEIROS DAS IES: SALÁRIOS, OUTRAS DESPESAS CORRENTES E CAPITAL}

A execução orçamentária das IES é organizada em grandes blocos de despesas: salários, outras despesas correntes e capital. As outras despesas correntes incluem a aquisição de material de consumo, o pagamento de serviços de terceiros (pessoas física e jurídica), pagamento de água, luz, telefone, fotocópia, internet, consertos de equipamentos, reparos em prédios etc.. As despesas de capital incluem a realização de obras, aquisição de equipamentos, material permanente, livros etc. (AMARAL, 2003).

No setor educacional o pagamento dos salários é responsável pela absorção da maior parte dos recursos; entretanto, é importante que sejam 
feitas comparações de como essas três fatias estão sendo repartidas nos países em estudo. A Tabela 6 mostra os percentuais dos recursos totais das instituições públicas que são gastos com esses três grandes blocos de despesas.

Tabela 6 - Recursos totais aplicados em salários, outras despesas correntes e capital (\%).

\begin{tabular}{|l|c|c|c|}
\hline País & $\begin{array}{c}\text { \% IES públicas com } \\
\text { salários }\end{array}$ & $\begin{array}{c}\text { \% IES públicas com outras } \\
\text { despesas correntes }\end{array}$ & $\begin{array}{c}\text { \% IES públicas } \\
\text { com capital }\end{array}$ \\
\hline Brasil & 69 & 20 & 11 \\
\hline OCDE & 60 & 29 & 11 \\
\hline Rússia & - & - & - \\
\hline Índia & - & - & - \\
\hline China & - & - & - \\
\hline África do Sul & - & - & - \\
\hline Chile & 62 & 33 & 5 \\
\hline Hungria & 59 & 32 & 9 \\
\hline México & 63 & 31 & 6 \\
\hline Turquia & 57 & 22 & 21 \\
\hline
\end{tabular}

Fonte: UNESCO, 2010.

Considerando que os países da OCDE já possuem uma situação mais bem estruturada e com valores financeiros elevados aplicados em todos os níveis educacionais, podemos considerar os seus percentuais como referência para os outros países, ou seja, em torno de $60 \%$ para pessoal, $30 \%$ para outras despesas correntes e $10 \%$ para capital. Quando os valores para o pagamento de salários são mais elevados, pode-se avaliar que os salários são mais altos ou que o volume total de recursos financeiros está pequeno e, portanto, o percentual associado aos salários se eleva.

Como, no Brasil, o volume de recursos aplicados na educação da população não é elevado (ver Tabela 1), pode-se supor que o volume de recursos aqui aplicados se dirige fortemente para o pagamento dos salários, sobrando valores menores para os outros blocos de despesas. Nesse caso, a inexistência de dados dos outros países do BRICS só permitem comparações do Brasil com países da OCDE.

A RELAÇÃO ALUNO/PROFESSOR

Um indicador que é observado quando se procura dimensionar o quadro de professores da educação superior de um país é a relação aluno/ professor. Como a própria OCDE afirma em Education at a Glance 2011 (OCDE, 
2011), essa informação é de difícil compilação pela diversidade existente no que se relaciona aos estudantes matriculados e aos contratos dos professores. Os estudantes matriculados podem fazer os cursos em regimes acadêmicos semestrais ou anuais, podem estudar meio período diário, períodos diários integrais ou mesmo estudar algumas poucas horas semanais. Os professores podem ser contratados em tempo parcial, tempo integral ou horistas etc.. Por outro lado, os cursos podem ser presenciais, a distância, modulados etc.. Além disso, é preciso examinar o perfil das IES do país. Elas se dedicam às atividades de ensino, pesquisa e extensão de forma indissociável, ou existem instituições que desenvolvem apenas atividades de ensino?

Esse é, portanto, um indicador que precisa ser examinado com cuidado, associando-o a outras informações institucionais como, por exemplo, o número de horas curriculares teóricas e práticas e qual a carga didática semanal média dos professores.

A Tabela 7 apresenta a relação aluno/professor para os países selecionados neste estudo.

Tabela 7 - Relação aluno/professor.

\begin{tabular}{|l|c|c|c|}
\hline País & Matrículas no tertiary & $\begin{array}{c}\text { Número de } \\
\text { professores }\end{array}$ & $\begin{array}{c}\text { Relação aluno/ } \\
\text { professor }\end{array}$ \\
\hline Brasil & 6.115 .138 & 345.335 & 17,7 \\
\hline "Bloco" da OCDE & 43.451 .807 & 2.955 .905 & 14,7 \\
\hline Rússia & 9.330 .115 & 669.970 & 13,9 \\
\hline Índia & 18.648 .923 & 538.769 & 34,6 \\
\hline China & 31.046 .735 & 1.556 .926 & 19,9 \\
\hline África do Sul & 876.243 & & - \\
\hline Chile & 424.679 & 37.607 & 23,3 \\
\hline Hungria & 2.705 .190 & 26.054 & 16,3 \\
\hline México & 2.924 .281 & 185.287 & 14,6 \\
\hline Turquia & & 164.285 & 17,8 \\
\hline
\end{tabular}

Fonte: UNESCO, 2010 e cálculos deste estudo.

Nota-se que o valor médio do "bloco" da OCDE é de 14,7 alunos por professor e pode também ser utilizado como referência. A Índia, com 34,6 alunos por professor, e o Chile, com 23,3, são os que oferecem as maiores sobrecargas de trabalho para os docentes (SGUISSARDI, 2009). A China, com 19,9, e o Brasil, com 17,7, apresentam, também, valores superiores aos da média dos países membros da OCDE. 


\section{CONSIDERAÇÕES FINAIS}

Se considerarmos os indicadores dos países da OCDE como referência para os indicadores da educação superior dos países emergentes que compõem o BRICS e, em especial para o Brasil, a análise dos diversos indicadores apresentados neste estudo mostrou que existem enormes desafios a serem vencidos pelo Brasil.

Com relação aos valores financeiros totais aplicados em educação pública, por pessoa em idade educacional, há uma distância muito grande entre a média dos países do "bloco" da OCDE e o Brasil. Há, portanto, que dois efeitos ocorram simultaneamente: a estabilidade da população com redução no número de crianças e jovens em idade educacional e crescimento da economia - no contexto capitalista -, para que um mesmo percentual do PIB signifique um volume maior de recursos financeiros a serem aplicados em educação. Os desafios se intensificam quando se examina a necessidade de se elevar o acesso da população a esse nível educacional. Isso só será possível, se for acoplado aos dois efeitos simultâneos descritos anteriormente, um terceiro efeito: a diminuição das desigualdades sociais existentes nos países em estudo.

O pagamento de bons salários àqueles que trabalham nas IES, além de uma relação aluno/professor que permita ao docente desenvolver atividades de pesquisa e de extensão são fundamentais para que esse nível educacional desenvolva suas atividades em elevados patamares de qualidade, propiciando a muitos países - como o Brasil, por exemplo - a produção do conhecimento e sua inserção na disputa mundial dentro desse campo.

Em geral, os países que destinam elevados volumes de recursos financeiros para a educação superior são também os que aplicam maiores recursos em pesquisa e desenvolvimento (OLIVEIRA e AMARAL, 2012). É preciso, portanto, que os países do BRICS percorram esses dois caminhos - posto que é essencial uma educação superior de alta qualidade e o desenvolvimento de pesquisas inovadoras em um mundo cada vez mais multipolar (LIMA, 2010) -, com vista a que os novos produtos e processos desenvolvidos possam compor a matriz tecnológica mundial, contribuindo para a melhoria da qualidade de vida das pessoas e para o desenvolvimento das nações de forma sustentável (MORHY, 2009). 
HIGHER EDUCATION IN BRAZIL: INPUT, INDICATORS AND COMPARISONS WITH OECD MEMBERS AND BRICS

ABSTRACT: The study presents a number of indicators related to higher education and compares the data from Brazil with those of OECD members and BRICS. The results of the analysis show that, in general, Brazil faces great challenges when its indicators are compared with those of OECD countries. It could be concluded that it will only be possible to reach OECD parameters when three effects occur simultaneously: population stability with a reduction in the number of children and young people of school going age; growth of the country and its GDP, in the context of global capitalism, and a reduction in existing social inequalities.

KEYWORDS: Higher Education. Indicators. Percentage of GDP. Budget.

\section{LAEDUCACIÓNSUPERIORENEL BRASIL:INSUMOS, INDICADORESYCOMPARACIONES CON PAÍSES DE LA OCDE Y DEL BRICS}

RESUMEN: El estudio presenta una serie de indicadores asociados a la educación superior y compara los datos del Brasil con aquellos de los países miembros de la OCDE y del BRICS. Los resultados de los análisis muestran que, por lo general, son grandes los desafíos del Brasil cuando se comparan los indicadores con los países de la OCDE. Se puede concluir que solo será posible alcanzar a los parámetros de la OCDE cuando ocurran, simultaneamente, tres efectos: estabilidad de la población con la disminución de niños y jóvenes en edad escolar; crecimiento del país y de su PIB, en el contexto del capitalismo mundial; y disminución de las desigualdades sociales existentes.

Palabras Claves: Educación Superior. Indicadores. Porcentaje del PIB. Presupuesto.

\section{NOTA}

1. Os valores US\$/PPP são aqueles valores em dólares que sofreram correções para obter a paridade do poder de compra (Purchasing Power Parity - PPP).

\section{REFERÊNCIAS}

AMARAL, N. C. Financiamento da educação superior: Estado X mercado. São Paulo e Piracicaba: Cortez e Unimep, 2003.

AMARAL, N. C. O novo PNE e o financiamento da educação no Brasil: os recursos como um percentual do PIB. In: III SEMINÁRIO BRASILEIRO DE EDUCAÇÃO. Campinas: Cedes / Unicamp, 28 fev. a 2 mar. 2011.

EUA.CIA. The World Factbook 2010. Disponível em: https://www.cia.gov/library/publications/the-world-factbook/region/region_soa.html, Central Intelligence Agency. Acesso em: 14 fev. 2010. 
HARVEY, D. Condição pós-moderna. São Paulo: Edições Loyola, 2000.

LIMA, M. R. S. Brasil e polos emergentes do poder mundial: Rússia, Índia, China e África do Sul. In: BAUMANN, R. (Org.). O Brasil e os demais BRICS: comércio e política. Brasília: Cepal; Ipea, 2010. cap. 7. p. 155-179.

MORHY, L. Universidade e desenvolvimento científico e tecnológico no Brasil. In: LAMARRA, N. F. (Org.). Universidad, sociedad e innovación: uma perspectiva internacional. Buenos Aires,. Argentina: Editora Universidad Nacional Tres Febrero (Eduntref), 2009. $511 \mathrm{p}$.

OCDE. Education at a Glance - 2011. Disponível em: http://www.oecd.org/document. Acesso em: 20 dez. 2011.

OLIVEIRA, J. F.; AMARAL, N. C. A produção do conhecimento no Brasil e no mundo: financiamento e políticas de ciência, tecnologia e inovação em debate. (Mimeografado) Goiânia, 2012.

SGUISSARDI, V. Universidade brasileira no século XXI: desafios do presente. São Paulo: Cortez, 2009.

THORSTENSEN, V. A defesa comercial dos BICs (Brasil, Índia e China): algumas lições para a política brasileira. In: Texto para discussão 1635, IPEA, Brasília-DF, 2011.

UNESCO. Banco de dados do Institute for Statistics / Data Centre. Disponível em: http:// stats.uis.unesco.org/unesco/TableViewer/document.aspx. Acesso em: 14 fev. 2010.

NELSON CARDOSO AMARAL: doutor em Educação pela Universidade Metodista de Piracicaba (Unimep); professor do Programa de Pós-graduação em Educação da Universidade Federal de Goiás.

E-mail: nelsoncardosoamaral@gmail.com 